\title{
Use of fermented quinoa flour for pasta making and evaluation of the technological and nutritional features
}

\section{Lorusso, Anna}

2017-05

Lorusso , A , Verni , M , Montemurro , M , Coda , R , Gobbetti , M \& Rizzello , C 2017 , ' Use of fermented quinoa flour for pasta making and evaluation of the technological and nutritional features ' , LWT-Food Science and Technology , vol. 78 , pp. 215-221 . https://doi.org/10.1016/j.lwt.2016.12.046

http://hdl.handle.net/10138/310591

https://doi.org/10.1016/j.lwt.2016.12.046

cc_by_nc_nd

acceptedVersion

Downloaded from Helda, University of Helsinki institutional repository.

This is an electronic reprint of the original article.

This reprint may differ from the original in pagination and typographic detail.

Please cite the original version. 
1 Use of fermented quinoa flour for pasta making and evaluation of the 2 technological and nutritional features

3

4

5 Anna Lorusso ${ }^{1}$, Michela Verni ${ }^{1}$, Marco Montemurro ${ }^{1}$, Rossana Coda ${ }^{2}$, Marco Gobbetti ${ }^{1}$, Carlo 6 Giuseppe Rizzello*1

7

$8{ }^{1}$ Department of Soil, Plant and Food Science, University of Bari Aldo Moro, 70126 Bari, Italy

$9 \quad{ }^{2}$ Department of Food and Environmental Sciences, University of Helsinki, Helsinki, Finland 10

16 *Corresponding author. Tel.: +39 0805442950; Fax: +390805442911

17

E-mail address: carlogiuseppe.rizzello@uniba.it

18

19

20 


\section{Abstract}

Pasta was prepared by replacing $20 \%$ of semolina with native and fermented quinoa flour and the effects of substitution on the technological and nutritional characteristics were evaluated. The addition of quinoa reflected the chemical composition of pasta, which had higher fiber, protein, and free amino acids content than semolina pasta, particularly in the case of pasta containing quinoa flour fermented with selected lactic acid bacteria. Furthermore, free amino acids, total phenols, and the antioxidant activity of pasta prepared with fermented quinoa flour were up to twice as high than the other types of pasta. When fermented quinoa flour was used, the water absorption during cooking was the lowest, even though cooking loss was also observed. The use of quinoa flour affected the textural characteristics of pasta, increased the tenacity and, when fermented, also the elasticity. The effects of quinoa fermentation were evident on the nutritional quality of fortified pasta, showing the highest in vitro protein digestibility, protein nutritional indices (Essential Amino Acid Index, Biological Value, Protein Efficiency Ratio, and Nutritional Index), as well as lowest predicted glycemic index. These results indicate the positive effect of fermented quinoa flour on pasta fortification.

Keywords: quinoa, pasta, lactic acid bacteria 


\section{Introduction}

Pasta has a primary role in human nutrition, thanks to its complex carbohydrate profile, the large global distribution, and the extended shelf life (Chillo, Laverse, Falcone, \& Del Nobile, 2008). The World Health Organization (WHO) and Food and Drug Administration (FDA) consider pasta a good vehicle for the addition of different nutrients to diet, since it can be fortified with protein, dietary fibers, vitamins and minerals (Chillo et al., 2008).

There is an increasing interest of producers, consumers, and the scientific community towards the addition of high-protein vegetable ingredients deriving from legumes and pseudocereals to pasta formulations (Chillo et al., 2008; Rizzello et al., in press; Valcárcel-Yamani \& da Silva Lannes, 2012; Wang \& Zhu, 2016). Even though fortification represents an efficient method to improve the nutritional quality of pasta, the replacement of semolina is still a challenge for the food industry (Rizzello et al., in press), since the addition of alternative ingredients markedly affects technological and sensory properties.

Quinoa is a pseudo-cereal originating from South America where its use as a staple food can be dated to pre-Hispanic times (Diaz et al., 2015). It has a high-protein content (14-16 g/100 g) (Chillo et al., 2008; Rizzello, Lorusso, Montemurro, \& Gobbetti, 2016a) and its amino acid composition, rich in histidine and lysine, is close to the ideal protein balance recommended by the FAO (Chillo et al., 2008; Rizzello et al., 2016a). Quinoa has a relatively high quantity of vitamins and minerals, iron and calcium (Chillo et al., 2008); moreover, lipids have a high quality, and are particularly rich in linoleate and linolenate (Chillo et al., 2008), having a linoleic:linolenic acid ratio which falls closer to the recommended values (5:1-10:1) for an healthy diet (Diaz et al., 2013). During the last years, the production of quinoa markedly increased, thus emphasizing its suitability for an extended cultivation in different climatic regions of North America, India, and Europe (Rizzello et al., 2016a; Stikic et al., 2012). Due to its nutritional quality, quinoa can have a role in functional food applications, which is an increasing trend in the developed world. Some studies have highlighted 
the potential of quinoa in gluten-free extruded food such as pasta (Schoenlechner, Drausinger, Ottenschlaeger, \& Jurackova, 2010) and corn-based snacks (Diaz et al., 2013).

Recently, quinoa flour sourdough fermented by autochthonous lactic acid bacteria (Rizzello et al., 2016a) was used for the enrichment of wheat bread. Free amino acids, soluble fibers, total phenols, phytase and antioxidant activities, and the in vitro protein digestibility, markedly increased during fermentation (Rizzello et al., 2016a). The results collected encouraged the use of quinoa and selected starters for the manufacture of novel and healthy products.

In this work, fermented quinoa flour was used for pasta fortification with the aim of enhancing its nutritional features. Fermentation with lactic acid bacteria has been previously applied to the manufacture of pasta with the aim to confer specific nutritional characteristics. Durum wheat semolina was fermented with a pool of selected lactic acid bacteria targeting gluten reduction (Curiel et al., 2014; Di Cagno et al., 2005) and Lactobacillus plantarum strains were used to produce vitamin B2-enriched pasta (Capozzi et al., 2011). In the present study, native and fermented quinoa flour were used as ingredients in semolina pasta manufacture aiming at evaluating the effects on the nutritional and technological properties of the fortified pasta. (1)

\section{Materials and methods}

\subsection{Raw materials and microorganisms}

Organic quinoa (Chenopodium quinoa) dehulled seeds imported from Argentina (Fundacion Nuevagestion, San Ignacio de Loyola, Jujuy) were used in this study. Quinoa flour (QF) obtained by milling with a M20 miller (IKA Werke GmbH and Co. KG, Staufen, Germany), was characterized by the follow proximal composition: moisture, $11.4 \mathrm{~g} / 100 \mathrm{~g}$; protein, $13.0 \mathrm{~g} / 100 \mathrm{~g}$; lipids, $5.0 \mathrm{~g} / 100 \mathrm{~g}$; total carbohydrates, $60.5 \mathrm{~g} / 100 \mathrm{~g}$; total dietary fibers, $8.4 \mathrm{~g} / 100 \mathrm{~g}$; ash, $0.6 \mathrm{~g} / 100$ g. 
Wheat (Triticum durum) semolina was purchased from Mininni mill (Altamura BA, Italy). Its proximate composition was: moisture, $10.2 \mathrm{~g} / 100 \mathrm{~g}$; protein, $12.1 \mathrm{~g} / 100 \mathrm{~g}$.; fat, $1.8 \mathrm{~g} / 100 \mathrm{~g}$; ash, 0.6 $\mathrm{g} / 100 \mathrm{~g}$ and total carbohydrates, $75.5 \mathrm{~g} / 100 \mathrm{~g}$.

Lactobacillus plantarum T6B10 and Lactobacillus rossiae T0A16 (previously isolated from quinoa flour) (Rizzello et al., 2016a) were used as starter for quinoa flour fermentation. The lactic acid bacteria strains were routinely propagated at $30^{\circ} \mathrm{C}$ in MRS broth (Oxoid, Basingstoke, Hampshire, England).

\subsection{Quinoa fermentation}

Prior to fermentation, L. rossiae T0A16 and L. plantarum T6B10 were cultivated at $30^{\circ} \mathrm{C}$ until the late exponential phase of growth was reached (approx. 12h). Cells were harvested by centrifugation $\left(10,000 \mathrm{x} \mathrm{g}, 10 \mathrm{~min}, 4^{\circ} \mathrm{C}\right)$ and washed twice in $50 \mathrm{mmol} / \mathrm{L}$ sterile potassium phosphate buffer $(\mathrm{pH}$ 7.0). The lactic acid bacteria cells were suspended in the water used for dough preparation and inoculated at an initial cell density of approx. $\log 7.0 \mathrm{cfu} / \mathrm{g}$ of dough. Quinoa dough was prepared by mixing quinoa flour and tap water with a dough yield (DY, dough weight x 100/flour weight) of 160, corresponding to 62.5 and $37.5 \mathrm{~g} / 100 \mathrm{~g}$ of flour and water, respectively. The dough was fermented at $30^{\circ} \mathrm{C}$ for $16 \mathrm{~h}$ and used as ingredient for pasta making as described below. The $\mathrm{pH}$ of quinoa dough was determined by a pHmeter (Model 507, Crison, Milan, Italy) with a food penetration probe. Total titratable acidity (TTA) was determined according to AACC method 0231.01 (AACC, 2010). Presumptive lactic acid bacteria were enumerated using MRS agar medium (Oxoid, Basingstoke, Hampshire, United Kingdom) supplemented with cycloheximide (0.1 g/L). Plates were incubated at $30^{\circ} \mathrm{C}$ for $48 \mathrm{~h}$, under anaerobiosis (AnaeroGen and AnaeroJar, Oxoid).

\subsection{Pasta making}

Experimental pasta was manufactured using a pilot plant La Parmigiana SG30 (Fidenza, Italy).

Formulas for doughs used for pasta making are reported in Table 1. All the doughs for pasta making 
were made with a DY of 130 , corresponding to a mixture of $23 \mathrm{~g} / 100 \mathrm{~g}$ water and $77 \mathrm{~g} / 100 \mathrm{~g}$ flour. A reference pasta was made only using wheat semolina (WP).

Two types of pasta containing quinoa were made: quinoa pasta $(\mathrm{QP})$ in which the $20 \%$ of semolina was replaced by native quinoa flour, and a fermented quinoa pasta (FQP), in which the fermented quinoa dough was added to obtain the same percentage of replacement of semolina with quinoa flour. Ingredients were mixed in three steps ( 1 min mixing and 6 min hydration). Then, the final dough was mixed for $30 \mathrm{~s}$ and extruded at $45-50^{\circ} \mathrm{C}$, through a $\mathrm{n} .76$ bronze die (150 $\mathrm{mm}$ diameter). The extruded material was cut with a rotating knife for short pasta shapes to obtain grooved "macaroni". For drying, pasta was arranged on frames (1.5 kg for frame) and treated according to the cycle described in Table $1 \mathrm{~S}$, at low temperature $\left(55^{\circ} \mathrm{C}\right)$.

\subsection{Hydration test, cooking time, cooking loss and water absorption.}

The method of Marti, Fongaro, Rossi, Lucisano, and Pagani (2011) (ratio pasta : water of 1:20, 180 min of incubation) was used to determine the hydration at $25^{\circ} \mathrm{C}$, while the method of Schoenlecher et al. (2010) was used to determine the cooking time. The optimal cooking time (OCT) corresponded to the disappearance of the white core. Cooking loss (expressed as grams of matter loss $/ 100 \mathrm{~g}$ of pasta) was evaluated by determining the amount of solids lost into the cooking water (Curiel et al., 2014). The increase of pasta weight during cooking (water absorption) was evaluated by weighing pasta before and after cooking. The results were expressed as $\left[\left(\mathrm{W}_{1}-\mathrm{W}_{0}\right) / \mathrm{W}^{0}\right]^{*} 100$, were $\mathrm{W}_{1}$ is the weight of cooked pasta and $\mathrm{W}_{0}$ is the weight of the uncooked samples.

\subsection{Chemical characteristics of pasta}

Total titratable acidity (TTA) was determined as mentioned in 2.2. Protein (total nitrogen $\times 5.7$ ), lipids, ash, total dietary fibers (TDF) and moisture contents were determined according to the AACC approved methods 46-11A, 30-10.01, 08-01, 32-05.01, and 44-15A, respectively (AACC, 
2010). The amount of total starch was determined using Ewers' polarimetric method (ISO 10520:1997).

A phosphate buffer extract, obtained by grinding pasta samples in $50 \mathrm{mmol} / \mathrm{L}$ phosphate buffer, 0.1 mol/L NaCl, $\mathrm{pH} 7.0$, was used for peptide and free amino acids (FAA) analyses. Peptide concentration was determined by the $o$-phthaldialdehyde (OPA) method (Church, Swaisgood, Porter, \& Catignani, 1983); FAA were determined by a Biochrom 30 series Amino Acid Analyzer (Biochrom Ltd., Cambridge Science Park, England) as described by Rizzello, Nionelli, Coda, Di Cagno, and Gobbetti (2010a).

The concentration of total phenols of pasta samples cooked until the OCT was determined on methanolic extracts (ME) as described by Slinkard and Singleton (1997), and expressed as gallic acid equivalent.

The 2,2-diphenyl-1-picrylhydrazyl (DPPH) radical scavenging activity was also determined on the methanolic extract (ME) of cooked pasta samples, as previously described by Rizzello, Nionelli, Coda, De Angelis, and Gobbetti (2010b).

\subsection{Texture and color analysis}

Instrumental Texture Profile Analysis (TPA) was carried out with a TVT-300XP Texture Analyzer (TexVol Instruments, Viken, Sweden), equipped with a cylindrical probe (diameter $95 \mathrm{~mm}$ ). For the analysis, pasta samples were cooked until the OCT, left to cool at room temperature and placed in a beaker (diameter, $100 \mathrm{~mm}$; height $90 \mathrm{~mm}$ ), filled to about half volume. The selected settings were the following: test speed $1 \mathrm{~mm} / \mathrm{s}, 30 \%$ deformation of the sample and two compression cycles (with a break of 30 s). TPA was carried out (Gámbaro, Feszman, Giménez, Varela, \& Salvador, 2004) using Texture Analyzer TVT-XP 3.8.0.5 software (TexVol Instruments).

The chromaticity co-ordinates of the samples (obtained by a Minolta CR-10 camera) were reported as color difference, $\Delta \mathrm{E}^{*}$ ab, calculated by equation (1), where $\Delta \mathrm{L}, \Delta \mathrm{a}$ and $\Delta \mathrm{b}$ are the differences for 

$\mathrm{L}$, $\mathrm{a}$ and $\mathrm{b}$ values between sample and reference (a white ceramic plate having $\mathrm{L}=93.4, \mathrm{a}=-1.8$ and $b=4.4)$.

$\Delta E * a b=\sqrt{(\Delta L)^{2}+(\Delta a)^{2}+(\Delta b)^{2}}$

\subsection{Nutritional characterization}

The in vitro protein digestibility (IVPD) of pasta samples, cooked until the OCT, was determined by the method of Akeson and Stahmann (1964) modified by Rizzello et al. (2014). The IVPD was expressed as the percentage of the total protein, which was solubilized after enzyme hydrolysis. The modified method of AOAC (2005) was used to determine the total amino acid profile of the digested protein fraction (Curiel et al., 2014). Amino acids were analyzed by a Biochrom 30 series Amino Acid Analyzer as described above. Since the above procedure of hydrolysis does not allow the determination of tryptophan, it was estimated by the method of Pinter-Szakács and Molnán-Perl (1990). Chemical Score (CS) estimates the amount of protein required to provide the minimal essential amino acids (EAA) pattern for adults, which was recently re-defined by FAO in 2007 (Millward, 2012). It was calculated using the equation of Block and Mitchel (1946). The sequence of limiting essential amino acids corresponds to the list of EAA, having the lowest chemical score (Block \& Mitchel, 1946). The protein score indicates the chemical score of the most limiting EAA present in the test protein (Block \& Mitchel, 1946). Essential Amino Acid Index (EAAI) estimates the quality of the test protein, using its EAA content as the criterion (Oser, 1959). EAAI was calculated according to the equation (2):

$E A A I=\sqrt{\frac{\left(E A A_{1} * 100\right)\left(E A A_{2} * 100\right)(\ldots)\left(E A A_{n} * 100\right)[\text { sample }]}{\left(E A A_{1} * 100\right)\left(E A A_{2} * 100\right)(\ldots)\left(E A A_{n} * 100\right)[\text { reference }]}}$

The Biological Value (BV) indicates the utilizable fraction of the test protein (Oser, 1959). BV was calculated using the equation (3):

$$
\mathrm{BV}=([1.09 * \mathrm{EAAI}]-11.70)
$$


194 The Protein Efficiency Ratio (PER) estimates the protein nutritional quality based on the amino acid 195 profile after hydrolysis. PER was determined using the equation (4), developed by Ihekoronye 196 (1981):

197 PER $=-0.468+(0.454 *[$ Leucine $])-(0.105 *[$ Tyrosine $])$

198 The Nutritional Index (NI) normalizes the qualitative and quantitative variations of the test protein 199 compared to its nutritional status. NI was calculated using the equation (5) of Crisan and Sands 200 (1978), which considers all the factors with an equal importance:

$201 \mathrm{NI}=(\mathrm{EAA} * \operatorname{Protein}(\mathrm{g} / 100 \mathrm{~g}) / 100)$

\subsection{Starch hydrolysis index and predicted glycaemic index}

204 The analysis of starch hydrolysis was carried out on pasta samples, cooked until the OCT with a procedure mimicking the in vivo digestion of starch (De Angelis et al., 2009). The degree of starch digestion was expressed as percentage of potentially available starch hydrolyzed at different times

$\mathrm{GI}=0.549 * \mathrm{HI}+39.71$

\subsection{Statistical analysis}

215 All the chemical and physical analysis were carried out in triplicate for each batch of pasta. Data were subjected to one-way ANOVA; paired-comparison of treatment means was achieved by Tukey's procedure at $\mathrm{P}<0.05$, using the statistical software Statistica 8.0 (StatSoft Inc., Tulsa, USA). 


\section{Results and discussion}

\subsection{Quinoa fermentation}

Prior incorporation to semolina flour for pasta production, quinoa flour dough was inoculated with L. plantarum T6B10 and L. rossiae T0A16 and fermented for $16 \mathrm{~h}$ at $30^{\circ} \mathrm{C}$. Compared with the beginning, the cell density of lactic acid bacteria increased during incubation (approx. 2 log cycles), up to $9.96 \pm 0.3 \log \mathrm{ufc} / \mathrm{g}$ of dough. The $\mathrm{pH}$ and TTA values of the quinoa flour dough before fermentation were $5.64 \pm 0.03$ and $7.7 \pm 0.2 \mathrm{~mL} 1 \mathrm{~mol} / \mathrm{L} \mathrm{NaOH}$, respectively. After incubation, $\mathrm{pH}$ decreased significantly $(\mathrm{P}<0.05)$ to $4.02 \pm 0.05$, while TTA increased to $27.7 \pm 0.3 \mathrm{~mL} 1 \mathrm{~mol} / \mathrm{L}$ $\mathrm{NaOH}$. L. plantarum T6B10 and L. rossiae T0A16 were isolated from quinoa matrices (Rizzello et al., 2016a) and already employed in quinoa flour fermentation thanks to the adaptability to the matrix and their pro-technological characteristics (acidification kinetic and efficiency in proteolysis). It was shown that, through their metabolic activities, L. plantarum T6B10 and $L$. rossiae T0A16 allowed the increase of the antioxidant and phytase activities and in vitro protein digestibility, and the degradation of condensed tannins in fermented quinoa dough (Rizzello et al., 2016a). Consequently, the use of fermented quinoa dough in breadmaking, markedly improved the biochemical, texture and sensory properties of enriched wheat bread (Rizzello et al., 2016a).

\subsection{Technological characterization}

The amount of high-protein flour that can substitute or can be added to semolina represents a compromise between nutritional improvement and achievement of satisfactory sensory and functional properties of the pasta (Chillo et al., 2008). According to previous researches, reporting a decrease of sensory and technological quality (Rizzello et al., 2016a; Stikic et al, 2012; ValcárcelYamani et al., 2012; Wang \& Zhu, 2016) in correspondence of high percentage of semolina replacement, experimental pasta was produced with $20 \mathrm{~g} / 100 \mathrm{~g}$ of quinoa. 
After extrusion, the $\mathrm{pH}$ of the pasta was $6.12 \pm 0.07,5.64 \pm 0.09$, and $4.74 \pm 0.04$ respectively for WP, QP, and FQP, while the TTA values were $2.1 \pm 0.2,4.2 \pm 0.1$, and $9.4 \pm 0.02 \mathrm{~mL} 1 \mathrm{~mol} / \mathrm{L}$ $\mathrm{NaOH}$ respectively for WP, QP, and FQP. Water absorption capacity was first investigated on the uncooked samples with the aim to evaluate how ingredients and processing conditions affected the structure of pasta (Marti et al., 2011). Indeed, it was reported that the ability of pasta to absorb water is affected by raw material composition and processing conditions, which can promote different micro- and macro-structures (e.g. porosity). Therefore, water absorption capacity is considered to be one of the most important characteristics for pasta (Marti et al., 2011). The kinetics of water uptake at $25^{\circ} \mathrm{C}$ are shown in Figure 1. No significant $(\mathrm{P}>0.05)$ differences were found among the pasta samples before $60 \mathrm{~min}$; then, the hydration of the pasta including quinoa was significantly $(\mathrm{P}<0.05)$ higher than WP. FQP had the highest hydration at $180 \mathrm{~min}(90 \pm 4 \mathrm{~g} / 100 \mathrm{~g})$, compared to QP and WP (7 and $16 \mathrm{~g} / 100 \mathrm{~g}$, respectively) (Figure 1). The relevant absorption of water by QP and FQP can be attributed to the abundance of hydrophilic molecules (e.g. FAA and small peptides, fibers) rather than to the effect of the processing conditions (forming and drying conditions) (Curiel et al., 2014).

The experimental OCT for WP resulted 8.7 min and a significant $(\mathrm{P}<0.05)$ decrease in OCT was found for pasta including quinoa flour (Table 2). Fortification of pasta with native quinoa flour led to a higher water absorption during cooking and a higher cooking loss compared to WP (Table 2). The opposite was observed when fermented quinoa was used and the water absorption during cooking was significantly $(\mathrm{P}<0.05)$ lower for FQP than WP and QP (Table 2$)$. The cooking loss of FQP resulted slightly but significantly $(\mathrm{P}<0.05)$ higher than $\mathrm{QP}$.

The weaker interaction between wheat proteins (mainly glutenins and gliadins) and quinoa proteins, mostly albumins and globulins (Diaz et al., 2013), might be the reason for the increased cooking loss (Wang \& Zhu, 2016). Moreover, the lowest absorption found for FQP might be due to a lower amount of starch compared to WP, and to a weaker protein network compared to QP, caused by proteolysis occurring during quinoa fermentation. 


\subsection{Chemical characterization}

The higher amount of proteins and fibers of quinoa flour compared to semolina reflected in both the fortified pasta, independently of fermentation (Table 2), in accordance with previous results obtained on bread (Rizzello et al., 2016a). Protein concentration increased (approx. 20\%) when quinoa flour was added to pasta and similar trend was found for dietary fiber and ash (Table 2). Starch concentration was higher in WP and decreased in pasta containing quinoa flour (Table 2). The proteolysis occurring during lactic acid bacteria fermentation caused the hydrolysis of the native proteins and a significant increase of peptides and FAA concentration. The lowest peptide amount was found for WP $(1.9 \pm 0.3 \mathrm{mg} / \mathrm{g}$ of pasta $)$ and the values significantly $(\mathrm{P}<0.05)$ increased when quinoa flour was added $(2.7 \pm 0.3$ and $7.1 \pm 0.4 \mathrm{mg} / \mathrm{g}$ of pasta, respectively for QP and FQP $)$. The same trend was observed for total FAA concentration, having the highest value in FQP $(720 \pm$ $20 \mathrm{mg} / \mathrm{kg}$ of pasta), which was up to 2-3 times higher than QP and WP $(329 \pm 10 \mathrm{mg} / \mathrm{kg}$ of pasta and $228 \pm 12 \mathrm{mg} / \mathrm{kg}$ of pasta, respectively). Compared to WP, the addition of quinoa flour caused an increase of the concentration of almost all the individual FAA (Figure 2), especially Thr, Glu, Cys, Arg, and Pro. In particular, the highest concentration of Ser, Pro, Arg, Glu, and Leu was found in FQP (Figure 2). The concentration of Lys, the most limiting amino acid in wheat flour, was $4.6 \pm$ $1.0,10.3 \pm 3.0$, and $34.0 \pm 2.7 \mathrm{mg} / \mathrm{kg}$ respectively in $\mathrm{WP}, \mathrm{QP}$, and FQP. Moreover, the use of quinoa flour, significantly $(\mathrm{P}<0.05)$ increased the amount of the functional $\gamma$-amino butyric acid (GABA) from $10 \pm 2 \mathrm{mg} / \mathrm{kg}$ (WP) to $28 \pm 3$ and $38 \pm 2 \mathrm{mg} / \mathrm{kg}$, respectively in QP and FQP (Figure 2). As determined through methanolic extraction, the total phenols concentration of QP was significantly higher than WP; moreover, a further increase was found when fermented quinoa was used (Table 2). As previously shown (Nionelli et al., 2014; Rizzello, Coda, Mazzacane, Minervini, \& Gobbetti, 2012), acidification during sourdough fermentation improves the extraction of total phenols, also as a consequence of the starters metabolic activity, able to hydrolyze complex phenolic compounds and their glycosylated forms into the corresponding phenolic acids. The 
increased solubilization of phenolics might be related to the highest antioxidant activity found in in FQP (Table 2).

\subsection{Textural properties}

Overall, the structural characteristics of fortified pasta are considered of great importance because, besides good sensorial attributes and low cooking loss, pasta of high quality must have low breakage susceptibility and good cooking resistance (Chillo et al., 2008).

The use of quinoa flour affected the TPA parameters (Table 2). WP had the lowest value of hardness, corresponding to the force required to compress pasta between teeth, and the presence of quinoa flour increased the hardness of ca 15\% in QP and 11\% in FQP. (Table 2). Resilience, defined as the ability of pasta to regain its original shape after first compression, was similar for WP and FQP, while it was significantly $(\mathrm{P}<0.05)$ lower in QP (Table 2). Fracturability was the lowest for WP, while no differences were found between QP and FQP. Cohesiveness, corresponding to the ability of the sample to resist to two different compressions, followed the same trend observed for resilience.

Overall, TPA demonstrated that quinoa flour increased the tenacity of pasta (hardness and fracturability parameters); when fermented, the overall elasticity (resilience and cohesiveness) was improved. The first effect was probably due to the increase of protein concentration; the second, to the modification caused on the protein network by the proteolysis occurring during fermentation (Rizzello et al., in press). A moderate increase of the cohesiveness, considered as a good indicator of how sample holds together upon cooking (Rizzello et al., in press), was found in pasta containing fermented quinoa flour compared to QP. As a consequence of quinoa flour addition, pasta color showed a different profile. The lightness $(L)$ of QP and FQP samples was lower $(\mathrm{P}<0.05)$ than WP (Table 2). An opposite trend was found for $\Delta \mathrm{E}^{*}$ ab, being the highest for FQP (Table 2).

Pasta samples were also analyzed for sensory properties through a panel test (see Supplementary Material) showing some peculiar traits conferred by quinoa flour. The sensory analysis revealed the 
overall acceptability of FQP, and the improvement of some flavor and taste attributes compared to QP.

\subsection{Nutritional characterization}

The IVPD gives information on the stability of protein hydrolysates, and on how they withstand to digestive processes. The digestible protein fraction was used for the determination of the protein quality indices. The addition of native quinoa flour decreased IPVD significantly $(\mathrm{P}<0.05)$ of approx. $15 \%$ compared to WP (Table 3 ). Nevertheless, when quinoa flour was fermented, the IVPD increased, compared to QP, and was slightly lower than WP. The increase of IVPD can be attributed to proteolysis, as already reported for quinoa (Rizzello et al., 2016a) and other protein sources (Coda et al., 2015; Rizzello et al., 2010a; Rizzello, Montemurro, \& Gobbetti, 2016b). The quality of proteins is considered one of the most important attribute for defining the nutritional characteristics of a food matrix. The amino acid composition has to be combined with protein digestibility for a better prediction of the nutritive value (Rizzello et al., 2014). Based on CS, the sequence of limiting amino acids for WP and QSP was found to be Lys, His, and Leu, while Lys Thr, and Val were the limiting amino acids for QP. Compared to WP, the addition of quinoa flour caused significant $(\mathrm{P}<0.05)$ increase of some of the CS (e.g. Lys, Met, Trp), particularly after fermentation, leading to the highest CS for FQP (Table 3).

Compared to WP, EAAI and BV were significantly $(\mathrm{P}<0.05)$ higher for $\mathrm{FQP}$, while the values for QP were intermediate. EAAI indicates the ratio of essential amino acids of the sample compared to the reference, while BV estimates the nitrogen potentially retained by human body after consumption. Also the PER, which reflects the capacity of a protein to support the body weight gain, was the highest for FQP. Within the indices that are used to evaluate the nutritional value of foods, NI combines qualitative and quantitative factors and it is considered a global predictor of the protein quality (Curiel et al., 2014). Since the protein bioavailability increased, the value of NI of FQP was significantly $(\mathrm{P}<0.05)$ higher than WP (Table 3). Starch hydrolysis, determined 
mimicking the in vivo digestion, represents a presumptive measure of the glycemic index (GI) in healthy subjects (De Angelis et al., 2009). Compared to white bread (WB), used as the analytical control and corresponding to a $\mathrm{HI}=100$, the $\mathrm{HI}$ value of WP was $72.9 \%$ and significantly $(\mathrm{P}<0.05)$ lower value was found for QP (67.4\%) and FQP (52.7\%). As a consequence, the predicted GI value of FQP was the lowest (Table 3). In general, GI depends on the food texture and particle size, type of starch, degree of starch gelatinization, physical entrapment of starch molecules within food, food processing and other ingredients (Petitot, Boyer, Minier, \& Micard, 2010). Pasta containing quinoa flour had a lower value of HI (and predicted GI) compared to control, probably due to the higher concentration of dietary fibers and resistant starch, and a further decrease was found when the fermented flour was used. This effect could be attributed to biological acidification, which is one of the main factors that decreases starch hydrolysis rate and HI (De Angelis et al., 2009).

\section{Conclusions}

Addition of $20 \mathrm{~g} / 100 \mathrm{~g}$ of quinoa flour to semolina was successful in improving the nutritional characteristics of pasta without compromising the technological and sensory quality. This study showed for the first time that fermentation with lactic acid bacteria was able to further enhance the positive effect of quinoa. Pasta containing fermented quinoa flour presented a higher nutritional profile compared to the other pasta, characterized by improved protein digestibility and quality, high nutritional scores, low predicted glycemic index and high antioxidant potential. A simple and low cost fermentation technology is a successful way to produce pasta with high nutritional potential, suitable to be included in the future food habits development.

\section{Funding}

This research did not receive any specific grant from funding agencies in the public, commercial, or not-for-profit sectors. 


\section{References}

AACC. (2010). Approved methods of analysis. St. Paul: Approved Methods Committee. Available from: http://methods.aaccnet.org/. Accessed 18.12.15.

Akeson, W. R., \& Stahmann, M. A. (1964). A pepsin pancreatin digest index of protein quality evaluation. Journal of Nutrition, 83, 257-261.

AOAC (2005). Official Methods of Analysis of AOAC International (18th ed.). AOAC International. Arlington, VA.

Block, R. J., \& Mitchel, H. H. (1946). The correlation of the amino acid composition of protein with their nutritive value. Nutrition Abstract and Reviews, 16, 249-278.

Capozzi, V., Menga, V., Digesu, A. M., De Vita, P., van Sinderen, D., Cattivelli, L., et al. (2011). Biotechnological production of vitamin B2-enriched bread and pasta. Journal of agricultural and food chemistry, 59, 8013-8020.

Capriles, V. D., \& Areas, J. A. (2013). Effects of prebiotic inulin-type fructans on structure, quality, sensory acceptance and glycemic response of gluten-free breads. Food \& Function, 4, 104110.

Chillo, S., Laverse, J., Falcone, P. M., \& Del Nobile, M. A. (2008). Quality of spaghetti in base amaranthus wholemeal flour added with quinoa, broad bean and chick pea. Journal of Food Engineering, 84, 101-107.

Church, F. C., Swaisgood, H. E., Porter, D. H., \& Catignani, G. L. (1983). Spectrophotometric assay using $o$-phthaldialdehyde for determination of proteolysis in milk and isolated milk proteins 1 . Journal of Dairy Science, 66, 1219-1227.

Coda, R., Melama, L., Rizzello, C. G., Curiel, J. A., Sibakov, J., Holopainen, U., et al. (2015). Effect of air classification and fermentation by Lactobacillus plantarum VTT E-133328 on faba bean (Vicia faba L.) flour nutritional properties. International Journal of Food Microbiology 193, $34-42$. 
Crisan, E. V., \& Sands, A. (1978). Biology and Cultivation of Edible Mushrooms. New York: 400 Academic Press Inc.

401 Curiel, J. A., Coda, R., Limitone, A., Katina, K., Raulio, M., Giuliani, G., et al. (2014).

402 Manufacture and characterization of pasta made with wheat flour rendered gluten-free using fungal 403 proteases and selected sourdough lactic acid bacteria. Journal of Cereal Science, 59, 79-87.

404 De Angelis, M., Damiano, N., Rizzello, C. G., Cassone, A., Di Cagno, R., \& Gobbetti, M. 405 (2009). Sourdough fermentation as a tool for the manufacture of low-glycemic index white wheat 406 bread enriched in dietary fibre. European Food Research and Technology, 229, 593-601.

Di Cagno, R., De Angelis, M., Alfonsi, G., De Vincenzi, M., Silano, M., Vincentini, O., et al. (2005). Pasta made from durum wheat semolina fermented with selected lactobacilli as a tool for a potential decrease of the gluten intolerance. Journal of Agricultural and Food Chemistry, 53, 43934402. (2013). Use of amaranth, quinoa and kañiwa in extruded corn-based snacks. Journal of Cereal Science, 58, 59-67.

Physical and sensory characteristics of corn-based extruded snacks containing amaranth, quinoa and kañiwa flour. LWT-Food Science and Technology, 64, 1047-1056.

Gámbaro, A., Feszman, S., Giménez, A., Varela, P., \& Salvador, A. (2004). Consumer acceptability compared with sensory and instrumental measures of white pan bread: sensory shelflife estimation by survival analysis. Journal of Food Science, 69, 401-405.

Ihekoronye, A. I. (1981). A rapid enzymatic and chromatographic predictive model for the invivo rat-based protein efficiency ratio. (Ph.D. Thesis). University of Missouri, Columbia International Standard: ISO 10520. (1997). Determination of starch content-Ewers polarimetric method. 
Marti, A., Fongaro, L., Rossi, M., Lucisano, M., \& Pagani, A. (2011). Quality characteristics of

dried pasta enriched with buckwheat flour. International Journal of Food Science and Technology, 46, 2393-2400.

Millward, D.J. (2012). Amino acid scoring patterns for protein quality assessment. British Journal of Nutrition, 108, S31-S43.

Nionelli, L., Curri, N., Curiel, J. A., Di Cagno, R., Pontonio, E., Cavoski, I., et al. (2014). Exploitation of Albanian wheat cultivars: characterization of the flours and lactic acid bacteria microbiota, and selection of starters for sourdough fermentation. Food Microbiology, 44, 96-107.

Oser, B. L. (1959). Protein and Amino Acid Nutrition. New York: Albanese Academic Press.

Petitot, M., Boyer, L., Minier, C., \& Micard, V. (2010). Fortification of pasta with split pea and faba bean flours: Pasta processing and quality evaluation. Food Research International, 43, 634641.

Pintér-Szakács, M., \& Molnán-Perl, I. (1990). Determination of tryptophan in unhydrolysed food and feed stuff by the acid ninhydrin method. Journal of Agricultural and Food Chemistry, 38, $720-726$.

Rizzello, C. G., Nionelli, L., Coda, R., Di Cagno, R., \& Gobbetti, M. (2010a). Use of sourdough fermented wheat germ for enhancing the nutritional, texture and sensory characteristics of the white bread. European Food Research and Technology, 230, 645-654.

Rizzello, C. G., Nionelli, L., Coda, R., De Angelis, M., \& Gobbetti, M. (2010b). Effect of sourdough fermentation on stabilisation, and chemical and nutritional characteristics of wheat germ. Food Chemistry, 119, 1079-1089.

Rizzello, C. G., Coda, R., Mazzacane, F., Minervini, D., \& Gobbetti, M., (2012). Micronized by-products from debranned durum wheat and sourdough fermentation enhanced the nutritional, textural and sensory features of bread. Food Research International, 46, 304-313. 
Rizzello, C. G., Curiel, J. A., Nionelli, L., Vincentini, O., Di Cagno, R., Silano, M., et al.

449 (2014). Use of fungal proteases and selected sourdough lactic acid bacteria for making wheat bread 450 with an intermediate content of gluten. Food Microbiology, 37, 59-68.

Rizzello, C. G., Lorusso, A., Montemurro, M., \& Gobbetti, M. (2016a). Use of sourdough made with quinoa (Chenopodium quinoa) flour and autochthonous selected lactic acid bacteria for enhancing the nutritional, textural and sensory features of white bread. Food Microbiology, 56, 113.

Rizzello, C. G., Montemurro, M., \& Gobbetti, M. (2016b). Characterization of the bread made with durum wheat semolina rendered gluten-free by sourdough biotechnology in comparison with commercial gluten-free products. Journal of Food Science, 81, H2263-2272.

Rizzello, C. G., Verni, M., Koivula, H., Montemurro M., Seppa, L., Kemell, M. et al. (in press). Influence of fermented faba bean flour on the nutritional, technological and sensory quality of fortified pasta. Food \& function.

Schoenlechner, R., Drausinger, J., Ottenschlaeger, V., Jurackova, K., \& Berghofer, E. (2010). Functional properties of gluten-free pasta produced from amaranth, quinoa and buckwheat. Plant Foods for Human Nutrition, 65, 339-349.

Slinkard, K., \& Singleton, V.L. (1997). Total phenol analysis: automation and comparison with manual methods. American Journal of Enology and Viticulture, 28, 49-55.

Stikic, R., Glamoclija, D., Demin, M., Vucelic-Radovic, B., Jovanovic, Z., MilojkovicOpsenica, D., et al. (2012). Agronomical and nutritional evaluation of quinoa seeds (Chenopodium quinoa Willd.) as an ingredient in bread formulations. Journal of Cereal Science, 55, 132-138.

Valcárcel-Yamani, B., \& da Silva Lannes, S. C. (2012). Applications of quinoa (Chenopodium Quinoa Willd.) and amaranth (Amaranthus spp.) and their influence in the nutritional value of cereal based foods. Food and Public Health, 2, 265-275.

Wang, S., \& Zhu, F. (2016). Formulation and quality attributes of quinoa food product. Food Bioprocess Tecnology, 9, 49-68. 


\section{Legends to figures}

Fig. 1. Kinetics of water absorption of pasta at $25^{\circ} \mathrm{C}$. WP, pasta made with durum wheat semolina (匹); QP, quinoa pasta in which $20 \%$ of semolina was replaced by native quinoa flour ( $\mathbf{\square})$; FQP, fermented quinoa pasta, in which the fermented quinoa dough was added to obtain the same percentage of replacement of semolina with quinoa flour ( $\mathbf{a})$. Data are the means of three independent analyses. ${ }^{\mathrm{a}-\mathrm{c}}$ Values with different superscript letters within the same time, differ significantly $(\mathrm{P}<0.05)$. Bars of standard deviations are also represented.

Fig. 2. Concentration of free amino acids and their derivatives $(\mathrm{mg} / \mathrm{kg})$ of pasta. WP, pasta made with durum wheat semolina (匹); QP, quinoa pasta in which the $20 \%$ of semolina was replaced by native quinoa flour ( $\mathbf{(})$; FQP, fermented quinoa pasta, in which the fermented quinoa dough was added to obtain the same percentage of replacement of semolina with quinoa flour ( $\mathbf{\square})$. Data are the means of three independent analyses. Three-letters amino acid code (IUPAC) is used. ${ }^{\text {a-c }}$ Values with different superscript letters within the same amino acid, differ significantly $(\mathrm{P}<0.05)$. Bars of standard deviations are also represented. 
Table 1. Formulas for pasta making. All the doughs had a final DY of 130, corresponding to 23 $\mathrm{g} / 100 \mathrm{~g}$ water and $77 \mathrm{~g} / 100 \mathrm{~g}$ flours mixture. WP, reference pasta made using only wheat semolina; QP, quinoa pasta in which the $20 \%$ of semolina was replaced by native quinoa flour; FQP, fermented quinoa pasta, in which the fermented quinoa dough was added to obtain the same percentage of replacement of semolina with quinoa flour.

\begin{tabular}{lccc}
\hline & WP & QP & FQP \\
\hline Semolina (g/100g) & 77 & 61.6 & 61.6 \\
Quinoa flour (g/100g) & - & 15.4 & \\
Fermented quinoa dough* (g/100g) & - & - & 24.64 \\
Water (g/100g) & 23 & 23 & 13.76 \\
\hline
\end{tabular}

Fermented quinoa dough (DY 160) was fermented at $30^{\circ} \mathrm{C}$ for $16 \mathrm{~h}$. Lactobacillus rossiae T0A16 and $L$. plantarum T6B10 were used as starters and inoculated at ca. $\log 7.0 \mathrm{cfu} / \mathrm{g}$. 
Table 2. Chemical, technological, textural characteristics and color analysis of pasta samples. WP, pasta made with durum wheat semolina; QP, quinoa pasta in which the $20 \%$ of semolina was replaced by native quinoa flour; FQP, fermented quinoa pasta, in which the fermented quinoa dough was added to obtain the same percentage of replacement of semolina with quinoa flour.

\begin{tabular}{|c|c|c|c|}
\hline & WP & QP & FQP \\
\hline \multicolumn{4}{|l|}{ Chemical characteristics } \\
\hline Dry matter (g/100g) & $91.56 \pm 0.21$ & $91.60 \pm 0.19$ & $91.58 \pm 0.08$ \\
\hline Proteins $(\mathrm{g} / 100 \mathrm{~g})$ & $10.27 \pm 0.14^{\mathrm{b}}$ & $12.4 \pm 0.13^{\mathrm{a}}$ & $12.3 \pm 0.07^{\mathrm{a}}$ \\
\hline Lipids $(\mathrm{g} / 100 \mathrm{~g})$ & $0.60 \pm 0.14^{\mathrm{b}}$ & $2.64 \pm 0.12^{\mathrm{a}}$ & $2.62 \pm 0.10^{\mathrm{a}}$ \\
\hline Starch $(\%)$ & $75.71 \pm 0.22^{\mathrm{a}}$ & $69.61 \pm 0.15^{b}$ & $69.21 \pm 0.18^{\mathrm{b}}$ \\
\hline Total dietary fibers $(\mathrm{g} / 100 \mathrm{~g})$ & $3.10 \pm 0.17^{\mathrm{b}}$ & $4.64 \pm 0.15^{\mathrm{a}}$ & $4.62 \pm 0.10^{\mathrm{a}}$ \\
\hline Ash $(g / 100 g)$ & $0.81 \pm 0.12^{\mathrm{b}}$ & $1.08 \pm 0.13^{\mathrm{a}}$ & $1.05 \pm 0.15^{\mathrm{a}}$ \\
\hline Total phenols (mmol/kg) & $2.21 \pm 0.18^{\mathrm{c}}$ & $3.02 \pm 0.21^{\mathrm{b}}$ & $4.06 \pm 0.22^{\mathrm{a}}$ \\
\hline Antioxidant activity ${ }^{1}$ & $14 \pm 1^{\mathrm{c}}$ & $26 \pm 2^{b}$ & $35 \pm 2^{\mathrm{a}}$ \\
\hline \multicolumn{4}{|l|}{ Technological characteristics } \\
\hline OCT (min) & $8.7 \pm 0.2^{\mathrm{a}}$ & $6.8 \pm 0.2^{b}$ & $7.0 \pm 0.1^{\mathrm{b}}$ \\
\hline Water absorption $(\mathrm{g} / 100 \mathrm{~g})$ & $128.6 \pm 3.7^{\mathrm{b}}$ & $135.3 \pm 3.4^{\mathrm{a}}$ & $118.0 \pm 4.5^{\mathrm{c}}$ \\
\hline Cooking loss (g of d.m./100g) & $5.01 \pm 0.11^{\mathrm{c}}$ & $6.01 \pm 0.12^{\mathrm{b}}$ & $6.21 \pm 0.04^{\mathrm{a}}$ \\
\hline \multicolumn{4}{|l|}{ Textural characteristics } \\
\hline Hardness $(\mathrm{N})$ & $3.31 \pm 0.06^{\mathrm{c}}$ & $3.80 \pm 0.09^{\mathrm{a}}$ & $3.68 \pm 0.05^{\mathrm{b}}$ \\
\hline Resilience & $0.28 \pm 0.04^{\mathrm{a}}$ & $0.22 \pm 0.05^{\mathrm{b}}$ & $0.27 \pm 0.04^{\mathrm{a}}$ \\
\hline Fracturability (N) & $2.02 \pm 0.24^{\mathrm{b}}$ & $2.32 \pm 0.07^{\mathrm{a}}$ & $2.33 \pm 0.09^{\mathrm{a}}$ \\
\hline Cohesiveness & $0.59 \pm 0.02^{\mathrm{a}}$ & $0.53 \pm 0.01^{b}$ & $0.60 \pm 0.02^{\mathrm{a}}$ \\
\hline \multicolumn{4}{|l|}{ Color analysis } \\
\hline $\mathrm{L}$ & $66.10 \pm 0.89^{\mathrm{a}}$ & $56.29 \pm 4.24^{b}$ & $50.69 \pm 2.35^{c}$ \\
\hline $\mathrm{a}$ & $-3.18 \pm 0.15^{b}$ & $-1.14 \pm 0.39^{a}$ & $-1.48 \pm 0.21^{\mathrm{a}}$ \\
\hline $\mathrm{b}$ & $19.34 \pm 0.51^{\mathrm{a}}$ & $16.48 \pm 1.49^{b}$ & $13.68 \pm 1.03^{\mathrm{c}}$ \\
\hline$\Delta \mathrm{e}$ & $30.08 \pm 0.85^{\mathrm{c}}$ & $38.52 \pm 4.24^{b}$ & $44.49 \pm 0.31^{\mathrm{a}}$ \\
\hline
\end{tabular}

The data are the means of three independent experiments \pm standard deviations $(n=3)$.

${ }^{1}$ The antioxidant activity was determined based on the scavenging activity towards DPPH radical after $10 \mathrm{~min}$ of reaction.

${ }^{\mathrm{a}-\mathrm{c}}$ Values in the same row with different superscript letters differ significantly $*(P<0.05)$ 
Table 3. Nutritional characterization of pasta. WP, pasta made with durum wheat semolina; QP, quinoa pasta in which the $20 \%$ of semolina was replaced by native quinoa flour; FQP, fermented quinoa pasta, in which the fermented quinoa dough was added to obtain the same percentage of replacement of semolina with quinoa flour.

\begin{tabular}{lccc}
\hline \multicolumn{1}{c}{ WP } & QP & QSP \\
\hline In vitro digestibility (\%) & $42.1 \pm 0.2^{\mathrm{a}}$ & $35.6 \pm 0.2^{\mathrm{c}}$ & $40.4 \pm 0.1^{\mathrm{b}}$ \\
Chemical score (\%) & & & \\
Histidine & $64 \pm 1^{\mathrm{b}}$ & $67 \pm 1^{\mathrm{b}}$ & $74 \pm 1^{\mathrm{a}}$ \\
Isoleucine & $89 \pm 1^{\mathrm{b}}$ & $87 \pm 2^{\mathrm{b}}$ & $120 \pm 3^{\mathrm{a}}$ \\
Leucine & $69 \pm 2^{\mathrm{c}}$ & $85 \pm 3^{\mathrm{b}}$ & $89 \pm 2^{\mathrm{a}}$ \\
Lysine & $29 \pm 1^{\mathrm{b}}$ & $36 \pm 2^{\mathrm{a}}$ & $391 \pm 2^{\mathrm{a}}$ \\
Cystine & $292 \pm 3^{\mathrm{b}}$ & $284 \pm 3^{\mathrm{b}}$ & $316 \pm 3^{\mathrm{a}}$ \\
Methionine & $74 \pm 2^{\mathrm{c}}$ & $80 \pm 1^{\mathrm{b}}$ & $89 \pm 1^{\mathrm{a}}$ \\
Phenylalanine + Tyrosine & $182 \pm 2^{\mathrm{a}}$ & $172 \pm 2^{\mathrm{b}}$ & $187 \pm 3^{\mathrm{a}}$ \\
Threonine & $72 \pm 1^{\mathrm{a}}$ & $59 \pm 1^{\mathrm{b}}$ & $76 \pm 2^{\mathrm{a}}$ \\
Valine & $82 \pm 1^{\mathrm{b}}$ & $64 \pm 1^{\mathrm{c}}$ & $93 \pm 2^{\mathrm{a}}$ \\
Tryptophan & $130 \pm 4^{\mathrm{c}}$ & $145 \pm 2^{\mathrm{b}}$ & $153 \pm 1^{\mathrm{a}}$ \\
Sequence of limiting EAA & & & \\
& Lysine & Lysine & Lysine \\
& Histidine & $T h r e o n i n e$ & $H i s t i d i n e$ \\
Essential Amino Acid Index (EAAI) & $44.5 \pm 0.4^{\mathrm{c}}$ & $46.8 \pm 0.3^{\mathrm{b}}$ & $50 \pm 0.3^{\mathrm{a}}$ \\
Biological Value (BV) & $36.8 \pm 0.3^{\mathrm{c}}$ & $39.60 \pm 0.1^{\mathrm{b}}$ & $45.7 \pm 0.2^{\mathrm{a}}$ \\
Protein Efficiency Ratio (PER) & $19.5 \pm 0.2^{\mathrm{c}}$ & $20.65 \pm 0.3^{\mathrm{b}}$ & $23.4 \pm 0.3^{\mathrm{a}}$ \\
Nutritional Index (NI) & $1.27 \pm 0.10^{\mathrm{b}}$ & $1.37 \pm 0.13^{\mathrm{b}}$ & $2.61 \pm 0.22^{\mathrm{a}}$ \\
Hydrolysis Index (HI) & $72.9 \pm 0.5^{\mathrm{a}}$ & $67.4 \pm 0.4^{\mathrm{b}}$ & $52.7 \pm 0.3^{\mathrm{c}}$ \\
Predicted Glycemic Index (pGI) & $79.7 \pm 0.8^{\mathrm{a}}$ & $76.7 \pm 0.6^{\mathrm{b}}$ & $68.5 \pm 0.5^{\mathrm{c}}$ \\
\hline
\end{tabular}

${ }^{\mathrm{a}-\mathrm{c}}$ Values in the same row with different superscript letters differ significantly $*(P<0.05)$ 


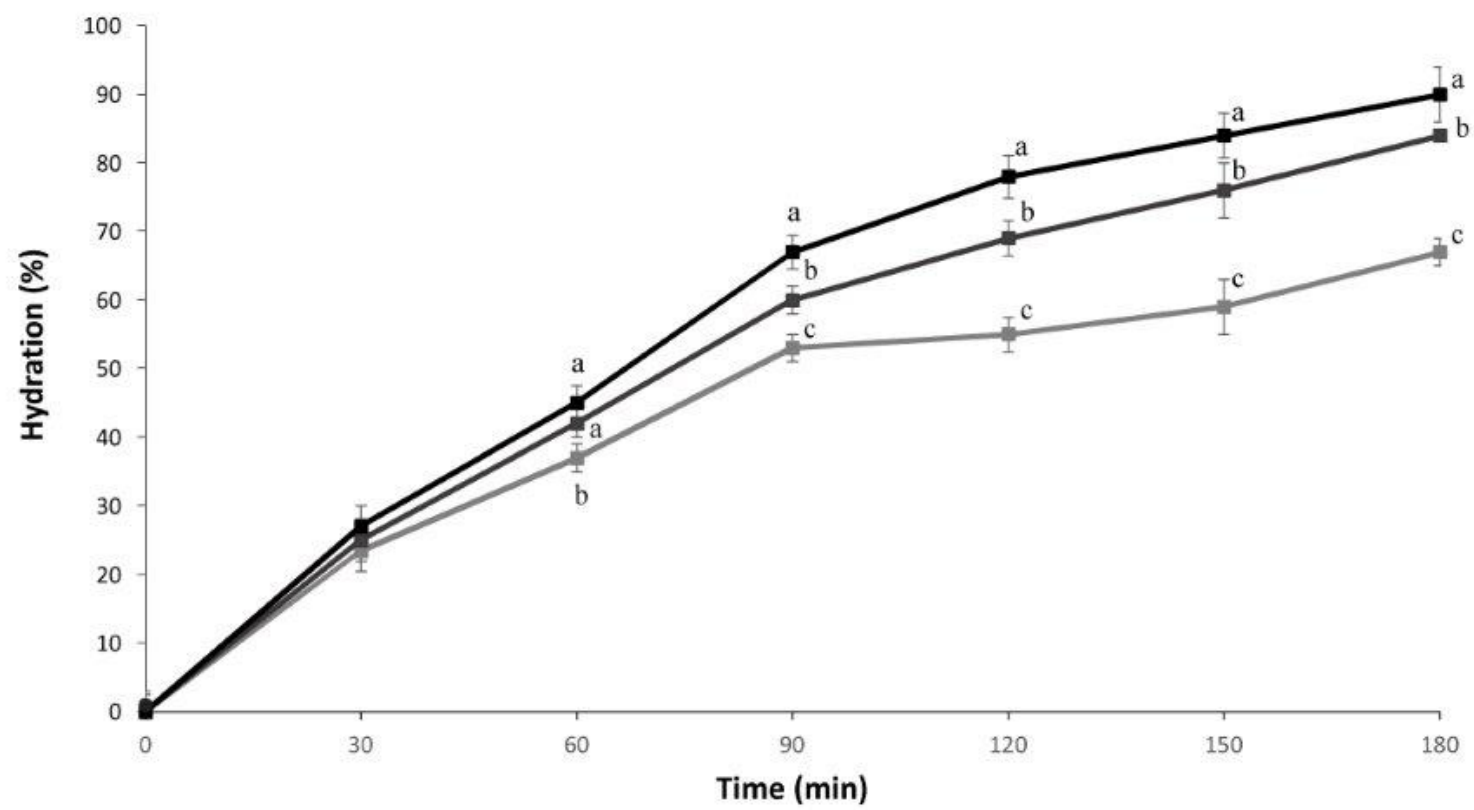

